\title{
Anticancer activity and computational modeling of ternary copper (II) complexes with 3-indolecarboxylic acid and 1,10-phenanthroline
}

\author{
ZHEN ZHANG $^{1}$, HUIYUN WANG ${ }^{1}$, QIBAO WANG $^{1}$, MAOCAI YAN $^{1,3}$, \\ HUANNAN WANG ${ }^{1}$, CAIFENG BI $^{2}$, SHANSHAN SUN ${ }^{1}$ and YUHUA FAN ${ }^{2}$ \\ ${ }^{1}$ School of Pharmacy, Jining Medical University, Rizhao, Shandong $276800 ;{ }^{2}$ Key Laboratory of \\ Marine Chemistry Theory and Technology, Ministry of Education, College of Chemistry and Chemical Engineering, \\ Ocean University of China, Qingdao, Shandong 266100, P.R. China; ${ }^{3}$ Department of Molecular Biology, \\ University of Southern California, Los Angeles, CA 90089, USA
}

Received March 21, 2016; Accepted May 16, 2016

DOI: $10.3892 / \mathrm{ijo} .2016 .3542$

\begin{abstract}
Metal-containing compounds have been extensively studied for many years as potent proteasome inhibitors. The $20 \mathrm{~S}$ proteasome, the main component of the ubiquitin proteasome pathway, is one of the excellent targets in anticancer drug development. We recently reported that several copper complexes were able to inhibit cancer-special proteasome and induce cell death in human cancer cells. However, the involved molecular mechanism is not known yet. We therefore synthesized three copper complexes and investigated their abilities on inhibiting proteasome activity and inducting apoptosis in human breast cancer cells. Furthermore, we employed molecular dockings to analyze the possible interaction between the synthetic copper complexes and the $\beta 5$ subunit of proteasome which only reflects the chymotrypsin-like activity. Our results demonstrate that three $\mathrm{Cu}(\mathrm{II})$ complexes possess potent proteasome inhibition capability in a dose-dependent and time-dependent manner in MDA-MB-231 human breast cancer cells. They could bind to the $\beta 5$ subunit of the $20 \mathrm{~S}$ proteasome, which consequently cause deactivation of the
\end{abstract}

Correspondence to: Dr Zhen Zhang, School of Pharmacy, Jining Medical University, 669 Xueyuan Road, Rizhao, Shandong 276800, P.R. China

E-mail: zhangzhen_1029@126.com

Dr Yuhua Fan, Key Laboratory of Marine Chemistry Theory and Technology, Ministry of Education, College of Chemistry and Chemical Engineering, Ocean University of China, 238 Songling Road, Qingdao, Shandong 266100, P.R. China

E-mail: fyh1959@163.com

Abbreviations: IC50, half maximal (50\%) inhibitory concentration of a substance; CT, chymotrypsin; MTT, 3-[4,5-dimethylthiazol-2yl]-2.5-diphenyl-tetrazolium bromide; PARP, polyclonal antibody against human poly(ADP-ribose) polymerase

Key words: anticancer, computational modelling, 3-indolecarboxylic acid, 1,10-phenanthroline, copper (II) complexes proteasome and tumor cell death. The present study is significant for providing important theoretical basis for design and synthesis of anticancer drugs with low toxicity, high efficiency and high selectivity.

\section{Introduction}

Metal complexes have important applications in many aspects of life. In recent years, the successful development of metalbased pharmaceuticals, including copper anticancer agents, has attracted more attention on metal complexes in cancer treatment (1-3). Studies have shown that the copper complexes, such as dithiocarbamate (4,5), 8-hydroxyquinoline (6), clioquinol (7) and some Schiff base copper coordination compounds (8-10), exert promising anticancer activity by targeting the ubiquitinproteasome pathway (UPP) in preclinical trials.

The UPP selectively mediates cellular protein degradation which regulates cell cycle progression, signal transduction, differentiation, proliferation and apoptosis (11). The tagged proteins are degraded by the $26 \mathrm{~S}$ proteasome, a huge cylinderlike protein complex, consists of one $20 \mathrm{~S}$ core particle and two $19 \mathrm{~S}$ regulatory particles (12). The $20 \mathrm{~S}$ core particle comprises four packed rings, and each ring consists of 7 distinct subunits: the outer two rings are $\alpha$ subunits, acting like a 'gate' and controlling which proteins may go through into the cylinder; the inner two rings are $\beta$ subunits, which form a catalytically active protease and are responsible for protein degradation (13). In proteasome of mammal cells, all $\alpha$ and $\beta$ subunits are distinct and only subunits $\beta 1, \beta 2$ and $\beta 5$ are catalytically active, which are responsible for caspase or peptidyl-glutamyl peptide-hydrolyzing (PGPH)-like activity, trypsin-like and chymotrypsin (CT)-like, respectively (14-16).

Previous research has demonstrated that the inhibition of proteasomal CT-like activity is closely associated with tumor cell apoptosis (17-20). Therefore, it is no surprise that selective inhibition of proteasome in cancer cells could be a potential anticancer strategy. To date, the full structure of human $20 \mathrm{~S}$ proteasome has not been reported yet. By BLAST sequence search against PDB library, bovine 20S proteasome (PDB code: 
1IRU) was discovered to have very high sequence homology to human $20 \mathrm{~S}$ proteasome, especially for the catalytic subunits, $\beta 1, \beta 2$ and $\beta 5$ (identity, $96.7,98.5$ and $98.0 \%$, respectively) (21). Despite a few differences, for example, $\beta 1 \mathrm{~V} 6 \mathrm{~A} / \mathrm{E} 205 \mathrm{G}$ and $\beta 2 \mathrm{C} 91 \mathrm{Y}$, these 3 subunits are completely identical between bovine and human. Thus, after some minor modifications and energy optimization, this bovine $20 \mathrm{~S}$ proteasome structure could be directly used as receptor of docking studies.

We previously reported that some metal complexes possess the ability to inhibit the CT-like activity of proteasome and induce cancer cell death in human cancer cells (22-25). However, the involved mechanism is unknown. Hence, our results prompted us to obtain further detailed understanding on such copper complexes as anticancer agent candidates. In the present study, we studied the effect of three ternary copper complexes with 3-indolecarboxylic and 1,10-phenanthroline in human breast cancer cells. Similar to the previous finding in prostate cancer cells, all these copper complexes could inhibit the CT-like activity of proteasome and induce apoptosis. Furthermore, molecular docking simulation was used to analyze the possible interaction between these complexes and the catalytically active $20 \mathrm{~S}$ proteasome. These three complexes were found to have best binding with catalytic site of subunit $\beta 5$ and formed a few hydrogen bonds and hydrophobic interactions with the receptor. Taken together, the information from the present study provides a basis for developing promising proteasome inhibitors in cancer treatment.

\section{Materials and methods}

Chemicals and reagents. 3-indoleacetic acid (IAA) and 3-indolepropionic acid (IPA), 3-indolebutyric acid (IBA) were purchased from J\&K Scientific Ltd. (Beijing, China). 1,10-Phenanthroline, DMSO and copper acetate were obtained from Aladdin Co. The complexes IAA-Cu-phen, IPA-Cuphen and IBA-Cu-phen were synthesized in Jining Medical University Pharmaceutical College (Rizhao, China) and were dissolved by DMSO to $25 \mathrm{mM}$. 3-[4,5-dimethylthiazol2-yl]2.5-diphenyl-tetrazolium bromide (MTT) were obtained from Sigma-Aldrich (St. Louis, MO, USA). The fluorogenic peptide substrate Suc-LLVY-AMC was obtained from Calbiochem (San Diego, CA, USA). Mouse monoclonal antibody to human poly(ADP-ribose) polymerase (PARP), mouse monoclonal antibody against ubiquitin (Ub), goat polyclonal antibody against $\beta$-actin (C-11) and all secondary antibodies were purchased from Cell Signaling Technology, Inc. (Shanghai, China).

Instruments. Infrared spectra were performed on a Nicolet 170-SX spectrophotometer using KBr pellets. ${ }^{1} \mathrm{H}$ NMR spectra were collected at a Bruker AVANCE III (600-MHz) spectrometer. ${ }^{13} \mathrm{C}$ NMR spectra were carried out with a Bruker AV600 (600-MHz) spectrometer. Thermal analyses were recorded on a NETZSCH thermal analyzer. Elemental chemical analysis (C, $\mathrm{H}$ and $\mathrm{N}$ ) were obtained on a Perkin-Elmer 2400 analyzer. Cellular changes were observed using a Zeiss Axiovert 25 microscope.

Synthesis of the complexes. The complexes were synthesized in two steps by following a previously described procedure (22).
In the first step, ligand IAA $(0.351 \mathrm{mg}, 2 \mathrm{mmol})$, IPA $(0.378 \mathrm{mg}$, $2 \mathrm{mmol})$, or IBA $(0.406 \mathrm{mg}, 2 \mathrm{mmol})$ were dissolved in ethyl alcohol to give a solution, respectively. $\mathrm{Cu}\left(\mathrm{CH}_{3} \mathrm{COO}\right)_{2} \cdot \mathrm{H}_{2} \mathrm{O}$ (0.199 mg, $1 \mathrm{mmol})$, dissolved in ethyl alcohol, was added dropwise to the above mentioned solution and reacted for $4 \mathrm{~h}$ to give a green solution. In the second step, $\mathrm{C}_{12} \mathrm{H}_{8} \mathrm{~N}_{2}(0.180 \mathrm{mg}$, $1 \mathrm{mmol}$ ) dissolved in ethyl alcohol, was added into the solution of the first step and then reacted for $3 \mathrm{~h}$ to give a green precipitate, which was filtered to give the product.

IAA-Cu-phen. $\left[\begin{array}{lll}\mathrm{Cu} & \left(\mathrm{C}_{10} \mathrm{H}_{8} \mathrm{O}_{2} \mathrm{~N}\right)_{2} & \left(\mathrm{C}_{12} \mathrm{H}_{8} \mathrm{~N}_{2}\right)\end{array}\right]$, $\mathrm{FW}=592.10 \mathrm{~g} \cdot \mathrm{mol}^{-1}$. Yield, 72\%. IR $\left(\mathrm{KBr}, \mathrm{cm}^{-1}\right): 3389.63$ $v(-\mathrm{NH}-) ; 1576.24 v_{\text {as }}\left(\mathrm{COO}^{-}\right) ; 1408.06 v_{\mathrm{s}}\left(\mathrm{COO}^{-}\right) ; 528.27$ $v(\mathrm{M}-\mathrm{N}) ; 476.85 \mathrm{v}(\mathrm{M}-\mathrm{O}) ;{ }^{1} \mathrm{H}$ NMR (DMSO, $\left.600 \mathrm{MHz}\right)$ : d (ppm) 10.736 (s, -NH-, indole ring); 8.931 (d, H-2, 9, 1,10-phenanthroline); 7.187 (s, H-5, 6, 1,10-phenanthroline); 7.352, 7.560 (d, $\mathrm{H}-4$, 7, indole ring); 6.813, 6.975 (t, H-5, 6, indole ring); 7.113 (d, H-2, indole ring); 3.367 (s, $-\mathrm{CH}_{2}$-indole ring); ${ }^{13} \mathrm{C} \mathrm{NMR}$ (DMSO): d (ppm) 184.35 (-COO); 155.28, 142.10, 133.14, 125.29 (1,10-phenanthroline carbons); 138.82, 127.41, 122.56, 121.27, 118.18, 117.93, 116.37 and 109.25 (indole ring carbons); $20.80\left(-\mathrm{CH}_{2}\right)$. TG analysis: residue $14.05 \%$ (calculated $13.43 \%$, $\mathrm{CuO})$. Anal. Calc. for $\mathrm{Cu}\left(\mathrm{C}_{10} \mathrm{H}_{8} \mathrm{O}_{2} \mathrm{~N}\right)_{2}\left(\mathrm{C}_{12} \mathrm{H}_{8} \mathrm{~N}_{2}\right)$ : C, 64.91; $\mathrm{H}$, 4.09; N, 9.46. Found (\%): C, 64.84; H, 4.21; N, 9.32. Molar conductivity: $\Lambda_{\mathrm{m}}\left(\mathrm{S} \bullet \mathrm{cm}^{-1} \bullet \mathrm{mol}^{-1}\right): 13.22$.

IPA-Cu-phen. [Cu $\left.\left(\mathrm{C}_{11} \mathrm{H}_{10} \mathrm{O}_{2} \mathrm{~N}\right)_{2} \quad\left(\mathrm{C}_{12} \mathrm{H}_{8} \mathrm{~N}_{2}\right)\right]$, $\mathrm{FW}=620.16 \mathrm{~g} \cdot \mathrm{mol}^{-1}$. Yield, 69\%. IR $\left(\mathrm{KBr}, \mathrm{cm}^{-1}\right): 3405.72$ $v(-\mathrm{NH}-) ; 1586.96 v_{\text {as }}\left(\mathrm{COO}^{-}\right) ; 1417.58 v_{\mathrm{s}}\left(\mathrm{COO}^{-}\right) ; 546.34$ $v(\mathrm{M}-\mathrm{N}) ; 497.64 v(\mathrm{M}-\mathrm{O}) ;{ }^{1} \mathrm{H}$ NMR (DMSO, $\left.600 \mathrm{MHz}\right)$ : d (ppm) 10.473 (s, -NH-, indole ring); 8.722 (d, H-2, 9, 1,10-phenanthroline); 7.262 (s, H-5, 6, 1,10-phenanthroline); 7.606, 7.398 (d, H-4, 7, indole ring); 6.877, 7.044 (t, H-5, 6, indole ring); 7.039 (d, H-2, indole ring); 4.372 (s, $-\mathrm{CH}_{2}$-indole ring); 3.420 (t, $-\mathrm{CH}_{2}$-indole ring). ${ }^{13} \mathrm{C}$ NMR (DMSO): $\mathrm{d}$ (ppm) 179.63(-COO); 157.32, 145.10, 140.81, 133.05 (1,10-phenanthroline carbons); 137.15, 129.38, 124.87, 119.04, 118.23, 117.65, 112.21 and 110.52 (indole ring carbons); 25.19, $22.66\left(-\mathrm{CH}_{2}\right)$. TG analysis: residue $13.26 \%$ (calculated $12.83 \%, \mathrm{CuO}$ ). Anal. Calc. for $\mathrm{Cu}\left(\mathrm{C}_{11} \mathrm{H}_{10} \mathrm{O}_{2} \mathrm{~N}\right)_{2}\left(\mathrm{C}_{12} \mathrm{H}_{8} \mathrm{~N}_{2}\right)$ : C, 65.85; H, 4.55; N, 9.03. Found (\%): C, 65.79; H, 4.60; N, 8.97. Molar conductivity: $\Lambda_{\mathrm{m}}$ $\left(\mathrm{S} \bullet \mathrm{cm}^{-1} \bullet \mathrm{mol}^{-1}\right): 8.29$.

IBA-Cu-phen. [ [ $\left.\mathrm{Cu} \quad\left(\mathrm{C}_{12} \mathrm{H}_{12} \mathrm{O}_{2} \mathrm{~N}\right)_{2} \quad\left(\mathrm{C}_{12} \mathrm{H}_{8} \mathrm{~N}_{2}\right)\right]$, $\mathrm{FW}=648.21 \mathrm{~g} \cdot \mathrm{mol}^{-1}$. Yield, 66\%. IR $\left(\mathrm{KBr}, \mathrm{cm}^{-1}\right): 3417.19$ $v(-\mathrm{NH}-) ; 1592.77 v_{\text {as }}\left(\mathrm{COO}^{-}\right) ; 1423.03 v_{\mathrm{s}}\left(\mathrm{COO}^{-}\right) ; 551.20 v(\mathrm{M}-\mathrm{N})$; 483.12 v(M-O); ${ }^{1} \mathrm{H}$ NMR (DMSO, $\left.600 \mathrm{MHz}\right)$ : d (ppm) 10.559 (s, -NH-, indole ring); 8.806 (d, H-2, 9, 1,10-phenanthroline); 7.224 (s, H-5, 6, 1,10-phenanthroline); 7.587, 7.390 (d, H-4, 7, indole ring); 6.846, 7.012 (t, H-5, 6, indole ring); 7.156 (d, H-2, indole ring); 4.437 (s, - $\mathrm{CH}_{2}$-indole ring); 3.382 (t, $-\mathrm{CH}_{2}$-indole ring); 3.053 (t, $-\mathrm{CH}_{2}$-indole ring). ${ }^{13} \mathrm{C}$ NMR (DMSO): $\mathrm{d}$ (ppm) 180.76 (-COO); 153.27, 141.01, 139.84, 129.69 (1,10-phenanthroline carbons); 137.92, 127.58, 123.30, 120.16, 118.88, 117.43, 112.87 and 109.53 (indole ring carbons); 26.44, 24.60, 21.55 $\left(-\mathrm{CH}_{2}\right)$. TG analysis: residue $12.80 \%$ (calculated $12.27 \%$, $\mathrm{CuO})$. Anal. Calc. for $\mathrm{Cu}\left(\mathrm{C}_{12} \mathrm{H}_{12} \mathrm{O}_{2} \mathrm{~N}\right)_{2}\left(\mathrm{C}_{12} \mathrm{H}_{8} \mathrm{~N}_{2}\right)$ : C, 66.70; H, 4.98; N, 8.64. Found (\%): C, 66.64; H, 5.08; N, 8.55. Molar conductivity: $\Lambda_{\mathrm{m}}\left(\mathrm{S} \bullet \mathrm{cm}^{-1} \bullet \mathrm{mol}^{-1}\right): 11.04$.

Cell culture and whole-cell extract preparation. MDA-MB-231 and MCF-7 breast cancer cells were grown at $37^{\circ} \mathrm{C}$ and $5 \% \mathrm{CO}_{2}$ in DMEM/F-12 (1:1) or RPMI-1640 (Invitrogen), respectively, 


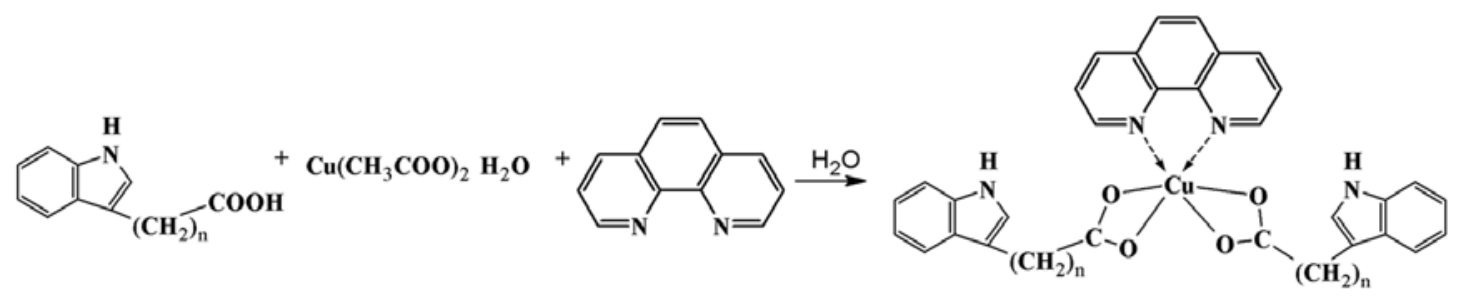

Figure 1. The general synthesis reaction and proposed structures of the three complexes. ( $n=1,2$ and 3$)$.

supplemented with $10 \%$ fetal bovine serum (FBS). A whole cell extracts were prepared and applied to assess the CT-like activity and western blot analysis (26).

Cell proliferation assay. MTT assay was applied to evaluate the antiproliferative effect of each complex on breast cancer cells. Cells were seeded in a 96-well plate and grown to $70-80 \%$ confluency, then treated with the indicated concentration of each complex at $37^{\circ} \mathrm{C}$. After cultured for $24 \mathrm{~h}$, cell proliferation was assessed as previously described (26).

Proteasome activity assay. Purified 20S human proteasome $(35 \mathrm{ng})$ or whole-cell extract $(10 \mu \mathrm{g})$ of human breast cancer cells were incubated with a series of concentrations of three copper complexes in $100 \mu \mathrm{l}$ of assay buffer $(20 \mathrm{mM}$ Tris- $\mathrm{HCl}, \mathrm{pH} 7.5)$ with $20 \mu \mathrm{M}$ fluorogenic peptide substrate Suc-LLVY-AMC. After 2-h incubation at $37^{\circ} \mathrm{C}$, the production of hydrolyzed AMC groups was measured as previously described (26).

Western blot analysis. MAD-MB-231 human breast cancer cells were treated with the complexes as already described (27). Proteins $(40 \mu \mathrm{g})$ were separated by SDS-PAGE and transferred to a nitrocellulose membrane. The expression of ubiquitin, PARP and $\beta$-actin were examined by western blot analysis.

Molecular docking. Sequence of human 20S proteasome $\beta$ subunits were retrieved from Protein KnowledgeBase (UniProtKB). For each subunit sequence, a BLAST search was performed on PDB library and bovine 20S proteasome [PDB code 1IRU (21)] was found to be the most homologous structure to human and was chosen for this docking study after some minor modifications. The small molecules were sketched manually and energy minimized and then docked to all three catalytic sites of the proteasome. Molecular docking was performed with the CCDC Gold 5.2 (28). Scoring function was set to ChemPLP, and other docking parameters were set to their default values. Accelrys Discovery Studio Visualizer 4.0 was used for result analysis and figure generation.

Statistical analysis. Statistical analysis was performed using Graphpad Prism 5 software. Differences between groups were analyzed using the Student's t-test.

\section{Results}

Synthesis and characterization of three complexes. 3-indolecarboxylic acid copper complexes could exhibit potent anticancer activity through inhibiting proteasome activity (22). Whereas the exact mechanism is still unknown, there is a hypothesis that the copper complexes interact with proteasome $\beta 5$ catalytically active subunit. At the same time, the length of linker between indole ring and carboxylic acid group has a certain impact on the activity of these complexes. In the present study, we synthesized three copper complexes with similar structure: IAA-Cu-phen, IPA-Cu-phen and IBA-Cu-phen (Fig. 1), among which IBA-Cu-phen is novel, and then compared their anticancer activity and investigated the potential mechanism of action. The obtained complexes were characterized by IR, ${ }^{1} \mathrm{H}$ NMR, ${ }^{13} \mathrm{C} \mathrm{NMR}$, TG analysis and elemental analysis. Because these compounds were not crystallized, X-ray diffraction was not performed.

According to the IR spectra data of ligands and complexes (IAA-Cu-phen, IPA-Cu-phen and IBA-Cu-phen), the strong absorption peaks at $3389.63,3405.81$ and $3417.19 \mathrm{~cm}^{-1}$, respectively, belong to the -NH- group. No significant shifts were observed on the peaks among these ligands, suggesting that nitrogen atom in the indole ring did not coordinate with copper. Compared with the IR spectra of the ligands, two new peaks in the range of $1576.24 \mathrm{~cm}^{-1}-1592.77 \mathrm{~cm}^{-1}$ and 1408.06 $\mathrm{cm}^{-1}-1423.03 \mathrm{~cm}^{-1}$ were assigned to $v_{\mathrm{as}}\left(\mathrm{COO}^{-}\right)$and $v_{\mathrm{s}}\left(\mathrm{COO}^{-}\right)$, respectively. In addition, the magnitude between $v_{\mathrm{as}}\left(\mathrm{COO}^{-}\right)$ and $v_{\mathrm{s}}\left(\mathrm{COO}^{-}\right)$was $<200 \mathrm{~cm}^{-1}$, indicating that the oxygen in $-\mathrm{COO}^{-}$group formed a coordination bond with copper ion, which is consistent with the literature (29).

The absorption vibration frequencies appeared at 476.85 , 497.64 or $483.12 \mathrm{~cm}^{-1}$ in these complexes were attributed to the formation of $\mathrm{Cu}-\mathrm{O}$ bond. A new peak at 528.27, 546.34 or $551.20 \mathrm{~cm}^{-1}$, respectively, appeared in these complexes, suggesting the formation of $\mathrm{Cu}-\mathrm{N}$ bond.

The ${ }^{1} \mathrm{H}$ NMR spectra of IAA-Cu-phen, IPA-Cu-phen and IBA-Cu-phen showed that there were small shifts in the signals among these ligands, suggesting the interaction between ligands and $\mathrm{Cu}(\mathrm{II})$ ion. In addition, the signal for -NH- proton in the spectra $(10.736,10.473$ and $10.559 \mathrm{ppm})$ were still present, while the signal for the $-\mathrm{COOH}$ proton of the ligands were absent in these complexes, indicating the hydrogen atom of carboxyl group were displaced by $\mathrm{Cu}$ (II) ion. In comparison with the ${ }^{1} \mathrm{H}$ NMR spectra of ligands, the signal of 1,10-phenanthroline did appear in these complexes, indicating there was coordination of 1,10-phenanthroline and $\mathrm{Cu}$ (II) ion. The ${ }^{1} \mathrm{H}$ NMR spectra analysis results were further supported by ${ }^{13} \mathrm{C}$ NMR spectra data $\left({ }^{1} \mathrm{H}\right.$ NMR and ${ }^{13} \mathrm{C}$ NMR data of the ligands IAA, IPA and IBA were not shown).

Thermal analysis (TG) of complexes IAA-Cu-phen, IPA-Cu-phen and IBA-Cu-phen were recorded in the range from 25 to $800^{\circ} \mathrm{C}$. These copper-containing compounds were all decomposed actually in one step and the residue rates of 

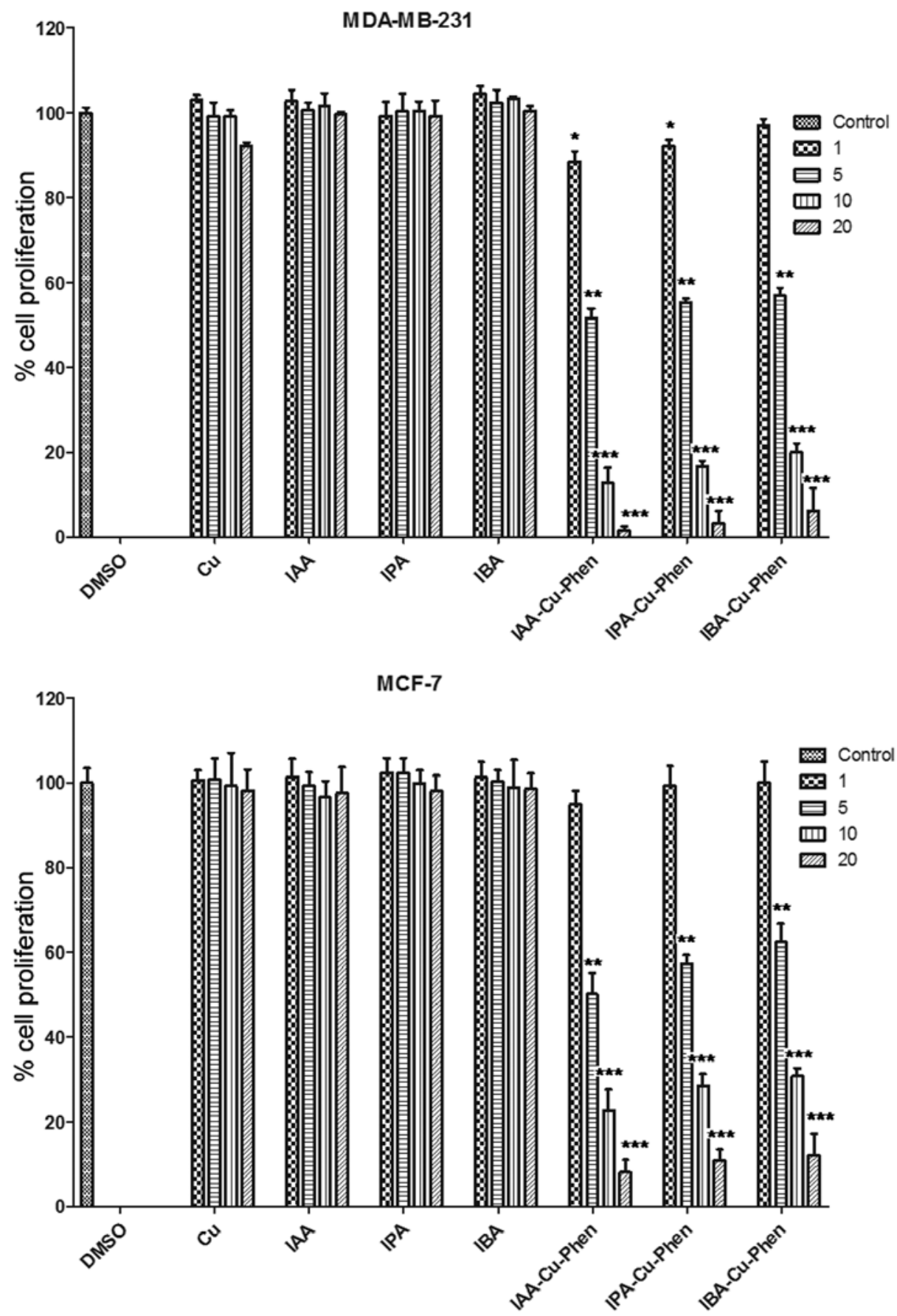

Figure 2. 3-(4,5-Dimethylthiazol-2-yl)-2,5-diphenyltetrazolium bromide (MTT) assay of MDA-MB-231 and MCF-7 cells treated with the ligands and complexes. MDA-MB-231 and MCF-7 cells were treated with each compound for $24 \mathrm{~h}$ at various concentrations as indicated. After $24 \mathrm{~h}$, the medium was removed, and the cells were treated with MTT solution, as described, dimethyl sulfoxide (DMSO) was used as a control. ${ }^{*} \mathrm{P}<0.05,{ }^{* * *} \mathrm{P}<0.01$ and ${ }^{* * * *} \mathrm{P}<0.001$, compared to control. Bars indicate the means \pm SD of 3 independent experiments.

them were $14.05,13.26$ and $12.80 \%$, respectively, which were consistent with the calculated values $(13.43,12.83$ and $12.27 \%)$.

Elemental analysis was applied to further confirm the composition of these copper complexes. The contents of carbon, hydrogen and nitrogen in each complex were consistent with the calculated values, which supported the proposed structure of these complexes.

The ligands and complexes were stable in air. Furthermore, all the complexes were soluble in DMSO and their molar conductivities $\left(\Lambda_{\mathrm{m}}\right)$ were $13.22,8.2$, and $11.04 \mathrm{~S} \cdot \mathrm{cm}^{2} \cdot \mathrm{mol}^{-1}$, respectively, which were $<35 \mathrm{~S} \cdot \mathrm{cm}^{2} \cdot \mathrm{mol}^{-1}(30)$.
Consequently, the complexes IAA-Cu-phen, IPA-Cu-phen and IBA-Cu-phen were considered as non-electrolytes and quite stable in culture medium.

Antiproliferative effect of the complexes in human breast cancer MDA-MB-231 and MCF-7 cell lines. We first studied effects of IAA-Cu-phen, IPA-Cu-phen, IBA-Cu-phen and their ligands on cell growth (Fig. 2). Human breast cancer MDA-MB-231 and MCF-7 cells were treated with 1, 5, 10 and $20 \mu \mathrm{M}$ (IAA-Cu-phen, IPA-Cu-phen, IBA-Cu-phen) as well as their ligands for $24 \mathrm{~h}$, followed by an MTT assay. We found 
Table $\mathrm{I} \mathrm{IC}_{50}$ values for cell death induction by copper compounds.

\begin{tabular}{lcc}
\hline & \multicolumn{2}{c}{ Cell death induction $\mathrm{IC}_{50}(\mu \mathrm{M})$} \\
\cline { 2 - 3 } Compound & MDA-MB-31 & MCF-7 \\
\hline $\mathrm{Cu}\left(\mathrm{CH}_{3} \mathrm{COO}\right)_{2}$ & No activity & No activity \\
IAA & No activity & No activity \\
IPA & No activity & No activity \\
IBA & No activity & No activity \\
IAA-Cu-phen & 4.20 & 5.21 \\
IPA-Cu-phen & 4.71 & 6.29 \\
IBA-Cu-phen & 5.31 & 6.82 \\
\hline
\end{tabular}

MDA-MB-231 and MCF-7 cells were treated with copper compounds for $24 \mathrm{~h}$, followed by measurement of cell death in a trypan blue exclusion assay.

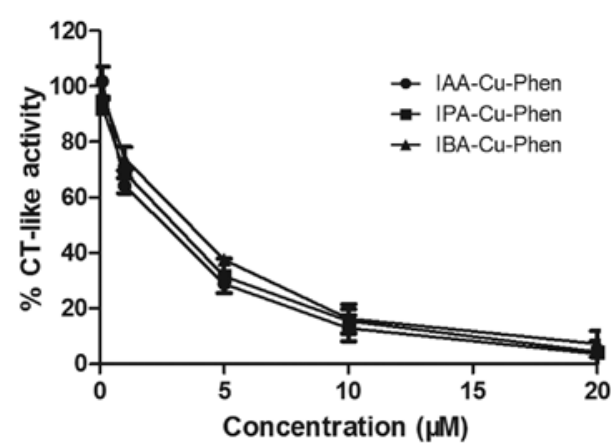

Figure 3. Purified 20S proteasome inhibition by the three complexes. Purified human proteasome (35 $\mathrm{ng}$ ) was incubated with DMSO or various concentrations of the three complexes for $2 \mathrm{~h}$, followed by proteasomal chymotrypsin-like activity assay. Bars indicate the means \pm SD of 3 independent experiments.

that these three complexes possessed similar growth-inhibitory activity with $>90 \%$ inhibition at $20 \mu \mathrm{M}$ in both cell lines in dose-dependent, compared to a control treated with DMSO (Fig. 2). However, IAA-Cu-phen was most potent, IPA-Cuphen came next, followed by IBA-Cu-phen while none of the ligands were active. The $\mathrm{IC}_{50}$ values for cell death induction by all the ligands and copper complexes are given in Table I.

In vitro inhibition of purified 20 S proteasomal chymotryspinlike activity. In this part of the present study, we investigated whether these three complexes could act as potent proteasome inhibitors and possess similar effects of proteasome inhibition as on cell proliferation. Purified human 20S proteasome were kept with various concentrations of the three complexes for $2 \mathrm{~h}$ and DMSO was used as a control. This result was consistent with MTT assays. The three complexes inhibited the 20S proteasomal chymotrypsin-like in vitro with rather similar $\mathrm{IC}_{50}(3.5-3.75 \mu \mathrm{M})$, and the inhibition ability increased along the concentration of these complexes (Fig. 3).

Inhibition of chymotrypsin-like activity and induction of apoptosis by the complexes in MDA-MB-231 breast cancer

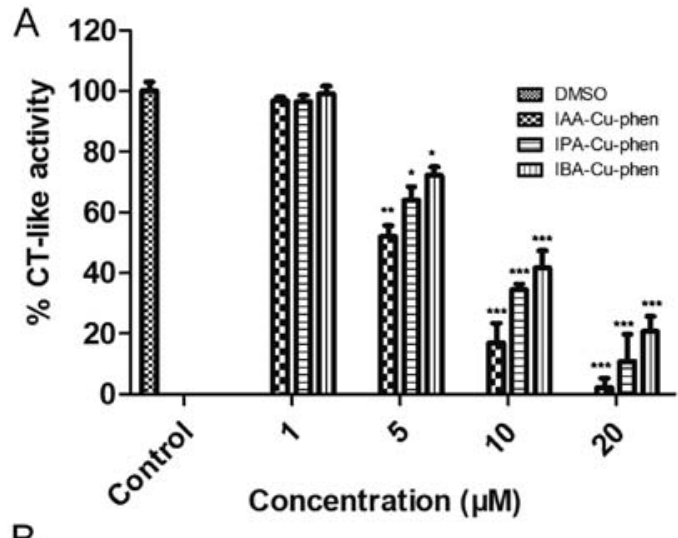

B IAA-Cu-phen IPA-Cu-phen IBA-Cu-phen
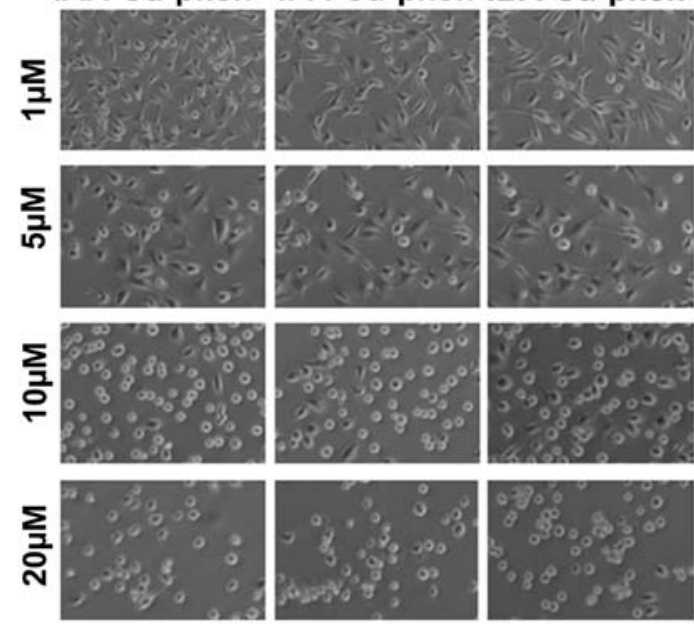

Figure 4. Concentration effects of the three copper complexes on breast negative cancer MDA-MB-231 cells. MDA-MB-231 cells were treated with DMSO (as control) or different concentrations of three copper complexes for 24 h. (A) Chymotrysin-like activity assay. ${ }^{*} \mathrm{P}<0.05,{ }^{* *} \mathrm{P}<0.01$ and ${ }^{* * * *} \mathrm{P}<0.001$, compared to control. Bars indicate the means \pm SD of 3 independent experiments. (B) Cellular morphologic changes.

cells. Chemical structures of several complexes could play a key role in inhibiting proteasome activity to some degree. Therefore, we studied the effects on cellular proteasomal CT-like inhibition and apoptosis induction of these three copper complexes with similar structures. Human breast cancer MDA-MB-231 cells were treated with three copper complexes at the concentrations of $1,5,10$ and $20 \mu \mathrm{M}$ for $24 \mathrm{~h}$ (DMSO as control), and cellular proteasomal CT-like activity and morphological changes were measured. The results indicated that all three complexes at $1 \mu \mathrm{M}$ showed no less than $5 \%$ inhibition of proteasomal CT-like activity (Fig. 4A) and no significant apoptosis-associated cellular morphology changes were observed (Fig. 4B). However, the abilities on the proteasome inhibition of these three copper complexes were obviously different at the concentrations of 5, 10 and $20 \mu \mathrm{M}$. We found that IAA-Cu-phen was the most potent, inhibiting 48, 83 and $98 \%$ (Fig. 4A), followed by IPA-Cu-phen, inhibiting 36\%, 66 and 89 (Fig. 4A), and the last was IBA-Cu-phen, with the degrees of inhibition being 28, 59 and 79\% (Fig. 4A), respectively. Consistently, cellular morphology changes (shrunken and rounded up) were found at concentrations of 5, 10 and $20 \mu \mathrm{M}$ (Fig. 4B). Our results suggested all three copper complexes possessed the ability to inhibit the proteasome 
A

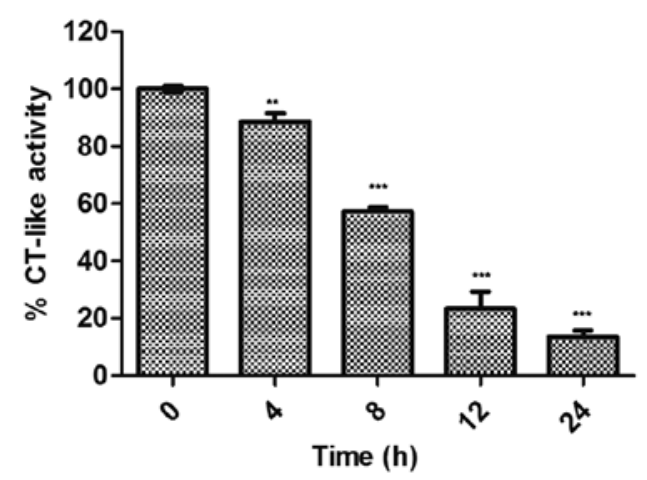

C

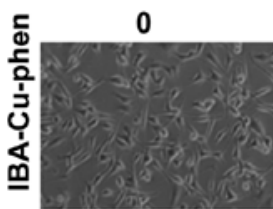

4

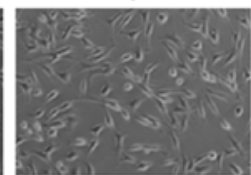

B

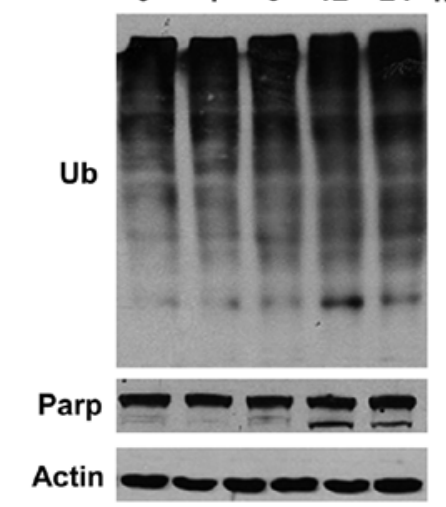

Figure 5. Kinetic effect of proteasome inhibition and apoptosis induction by the complex IBA-Cu-phen in MDA-MB-231 cells. MDA-MB-231 cells were exposed to $20 \mu \mathrm{M}$ of IBA-Cu-phen for the indicated times. (A) Proteasomal chymotrypsin-like activity assay. ${ }^{* *} \mathrm{P}<0.01$ and ${ }^{* * * *} \mathrm{P}<0.001$, compared to control. Bars indicate the means \pm SD of 3 independent experiments. (B) Western blot assay (ubiquitin, PARP and $\beta$-actin), and (C) the apoptosis morphologic changes.
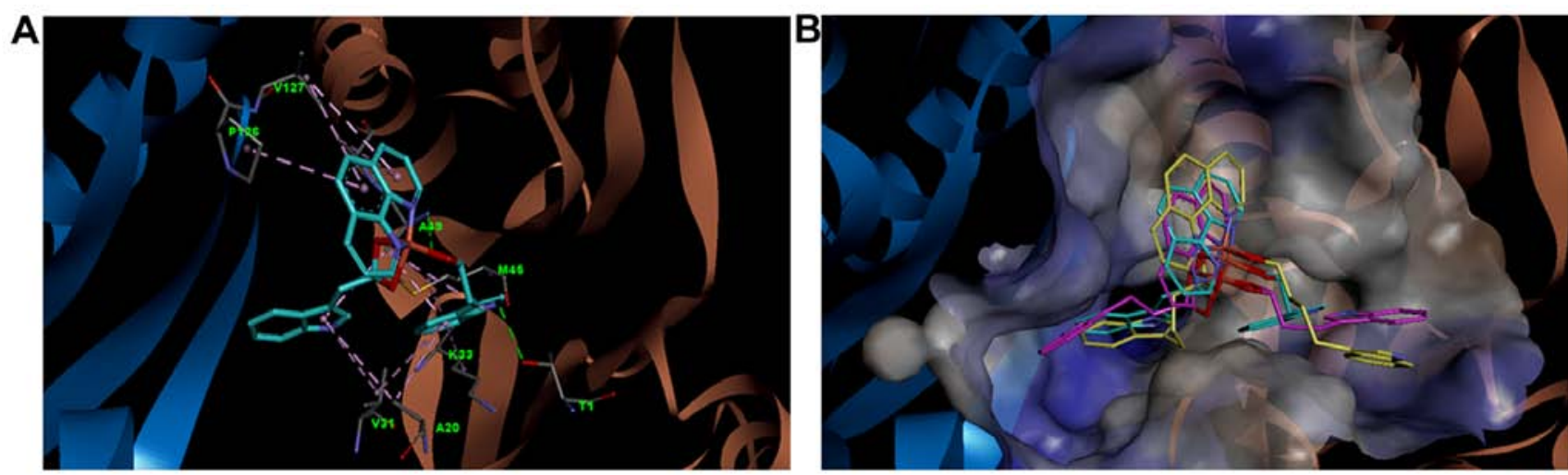

Figure 6. Molecular docking simulation. (A) Binding mode of IAA-Cu-phen to $20 \mathrm{~S}$ proteasome $\beta 5$ catalytic site. The $\beta 5$ and $\beta 1$ subunits are colored orange and sky blue, respectively. The non-bond interactions of ligand IAA-Cu-phen with amino acid residues are displayed; the green dashes indicate hydrogen bonds, while the light violet dashes indicate hydrophobic interactions. (B) Comparison of binding mode of ligand IAA-Cu-phen, IPA-Cu-phen and IBA-Cu-phen. The $\beta 5$ and $\beta 1$ subunits are colored orange and sky blue, respectively. The molecular surface of $20 \mathrm{~S}$ proteasome binding pocket is displayed, as well as the conformation of ligand IAA-Cu-phen (cyan stick), IPA-Cu-phen (magenta stick) and IBA-Cu-phen (yellow stick) in the binding pocket.

activity and induce apoptosis in a dose-dependent manner with the order IAA-Cu-phen >IPA-Cu-phen >IBA-Cu-phen.

Kinetic effect of the complexes on proteasome inhibition and apoptosis induction. Previous studies have shown that the decrease of CT-like activity in proteasome is associated with induction of tumor cell apoptosis (5,17-20). Herein, we performed a kinetic experiment to investigate whether the new complex IBA-Cu-phen possessed the same effect. MDA-MB231 cells were treated with $20 \mu \mathrm{M}$ compound for $0,4,8,12$ or $24 \mathrm{~h}$, followed by measurement of proteasomal inhibition and cell apoptosis (Fig. 5). The result showed that IBA-Cu-phen inhibited $\sim 12 \%$ of proteasome activity after 4 -h treatment (Fig. 5A). As time went on, the chymotrypsin-like activity further decreased. The inhibition ratios were 43,77 and $86 \%$ at 8,12 and $24 \mathrm{~h}$, respectively. Consistently, the accumula- tion of ubiquitinated proteins were also detected at $4 \mathrm{~h}$ and the levels increased gradually at later time-points (Fig. 5B). However, cellular apoptosis morphological changes (Fig. 5C) and apoptosis-specific PARP cleavage (Fig. 5B) both appeared at $12 \mathrm{~h}$ and later time-point of treatment. These results demonstrate that proteasome inhibition by IBA-Cu-phen triggers the occurrence of tumor cell apoptosis.

Molecular docking simulation. To further explain how and why these three copper complexes could serve as proteasomal CT-like inhibitors, we investigated the possible binding mode of the three compounds with proteasome by molecular docking simulation. The small molecules IAA-Cu-phen, IPA-Cu-phen and IBA-Cu-phen were docked to all the three catalytic site of the above receptor structure using CCDC GOLD 5. These three small molecules were found to have the best binding 


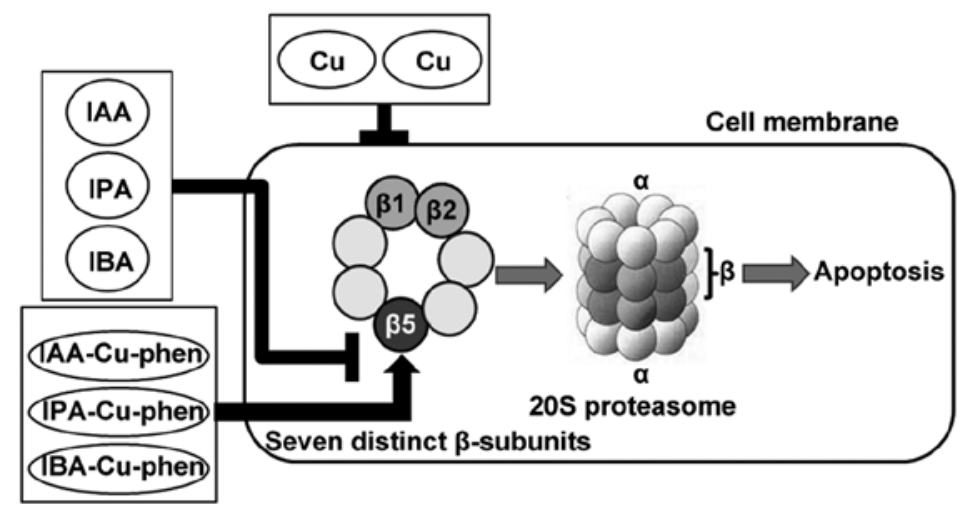

Figure 7. Working model for the antitumor action of ligands, copper and three complexes in breast cancer cells. See Discussion for details.

with catalytic site of subunit $\beta 5$, which locates near the adjacent subunit $\beta 1$ and also consists of a number of residues from subunit $\beta 1$, like SER123, ASP125, PRO126, VAL127 and GLN131 (Fig. 6).

The binding mode of IAA-Cu-phen, which has the highest activity among all three complexes, was analyzed. As shown in Fig. 6A, IAA-Cu-phen forms a few hydrogen bonds and hydrophobic interactions with the receptor. Briefly, it forms a hydrogen bond with THR1 sidechain by its indole nitrogen atom; also, its carboxylic oxygen atom (which coordinates with copper), forms a hydrogen bond with ALA49, which plays an important role in IAA-Cu-phen binding. Residues ALA20, VAL31, LYS33 and MET45 form a large hydrophobic cavity with their sidechains, to accommodate one indole ring of IAA-Cu-phen and bind it with hydrophobic interactions. The naphthisodiazine group of IAA-Cu-phen binds to ALA50 and two residues from subunit $\beta 1$ (PRO126 and VAL127) through hydrophobic interactions. Furthermore, binding modes of three complexes were compared. As displayed in Fig. 6B, IAA-Cu-phen, IPA-Cu-phen and IBA- $\mathrm{Cu}$-phen in proteasome catalytic pocket have similar binding conformations, but differ in the position and orientation of the two terminal indole rings. IAA-Cu-phen binds to the pocket tightly, while IBA-Cu-phen shows a little weaker binding to the pocket than IAA-Cu-phen and IPA-Cu-phen. These results agree with the biological study results.

\section{Discussion}

The ubiquitin-proteasome pathway is responsible for selectively degradation of intracellular proteins, and has attracted extensive interest in cancer therapeutics $(1,31)$. Some studies indicate that cancer cells are more dependent on the UPP than normal cells $(18,32)$. Therefore, inhibition of proteasome activity could be a viable option in treatment of human cancer. The first proteasome inhibitor bortezomib (Velcade) was successfully applied clinically and used in relapsed multiple myeloma treatment (33), and this raised concerns over the development of proteasome inhibitor. The second-generation proteasome inhibitors carfilzomib (Kyprolis ${ }^{\circledR}$ ) (34) and Ninlaro (ixazomib) $(35,36)$ were developed and approved by the USFDA in 2012 and 2015, respectively. But, unfortunately, the emergence of drug resistance makes treatment less effective and limits their clinical use. Based on the development of the antitumor metal-based drugs, designing and developing novel metal-based complexes as a new generation proteasome inhibitor could be a good choice (20).

Recent studies suggest that some copper complexes could serve as potential proteasome inhibitors due to their potent effect in the inhibition of proteasome and induction of cancer cell apoptosis (22), although the detailed mechanism of action remained unclear. Hence, in order to further investigate the anticancer effect of this kind of copper complexes and to understand the mechanisms by which these three complexes inhibit the proteasomal activity and induce cell death, in the current study we synthesized three $\mathrm{Cu}$ (II) complexes IAA-Cuphen, IPA-Cu-phen and IBA-Cu-phen using IAA, IPA and IBA as ligands, and have shown that they exert very potent growth-inhibitory activity in both ER-negative MDA-MB-231 and ER-positive MCF-7 cells. IAA-Cu-phen was the most potent, IPA-Cu-phen came next, followed by IBA-Cu-phen with none of the ligands active (Fig. 2 and Table I). In fact, these complexes possess similar structures. Therefore, the length of linker between indole ring and carboxylic acid group may have a certain impact in the activity of these complexes.

We extended this knowledge and investigated the potential proteasome-inhibitory activity of these copper complexes in vitro and in vivo. We found that three complexes were potent in their ability to inhibit the CT-like activity of purified 20S proteasome and the cellular proteasome in concentration-dependent effect (Figs. 3 and 4A). In addition, cellular morphologic changes were observed at 10 and $20 \mu \mathrm{M}$ (Fig. 4B), indicating cellular apoptosis induction. Correlating positively with the anti-proliferation assay, these complexes inhibited proteasome activity and induce apoptosis with the order IAA-Cu-phen >IPA-Cu-phen >IBA-Cu-phen. Then, we performed a kinetic experiment to test whether tumor cell apoptosis was caused by the proteasome inhibition of IBA-Cuphen. MDA-MB-231 cells were treated with IBA-Cu-phen, the proteasomal CT-like activity was inhibited at as early as $4 \mathrm{~h}$ (Fig. 5A), and this was associated with accumulation levels of ubiquitinated proteins (Fig. 5B). However, cleavage fragment p85 of PARP was observed at 8-h treatment and later time-points, indicating apoptosis occurrence, which also complemented well with the morphologic changes (Fig. 5C).

Currently, the related mechanism of action for the $\mathrm{Cu}$ complexes is still unclear. The first orally bioavailable and reversible proteasome inhibitor, ixazomib, acts by binding to 
and inhibiting the $\beta 5$ subunit of the $20 \mathrm{~S}$ proteasome $(36,37)$. The discovery encouraged us to further study whether the copper complexes could bind to the $\beta 5$ subunit of the $20 \mathrm{~S}$ proteasome. Therefore, we investigated the possible binding mode of the three active compounds to proteasome by molecular docking simulation. The bovine $20 \mathrm{~S}$ proteasome, which was discovered to have very high sequence homology to human $20 \mathrm{~S}$ proteasome, especially for the catalytic subunits, $\beta 1, \beta 2$ and $\beta 5$, was used as receptor of docking studies. We found that these three complexes have best binding with catalytic site of subunit $\beta 5$, which locates near the adjacent subunit $\beta 1$ (Fig. 6). These three complexes could form a few hydrogen bonds and hydrophobic interactions with the receptor and directly inhibit chemotrypsin-like activity (Fig. 6A). The binding conformations of three copper complexes in proteasome catalytic pocket are roughly similar, but differ in the position and orientation of the two terminal indole rings (Fig. 6B). Furthermore, such differences may be due to the different length of linker between indole ring and carboxylic acid group. IAA- $\mathrm{Cu}$-phen binds to the pocket tightly, while IBA-Cu-phen shows a little weaker binding affinity to the pocket than IAA-Cu-phen and IPA-Cuphen, probably due to the larger freedom of movement of the indole rings. This result may indicate that the extra rotatable bond(s) of IPA-Cu-phen and IBA-Cu-phen is unnecessary or detrimental. But in general, seen from the molecular modeling results, binding ability of IPA-Cu-phen and IBA-Cu-phen do not differ much to that of IAA-Cu-phen, which agree with the biological study results.

As stated earlier, the ligands IAA, IPA and IBA have no activity on inhibiting tumor cell proteasome or inducing apoptosis. It is known that $\mathrm{CuCl}_{2}$ alone was not able to induce any of these events (5) but inhibited the CT-like activity of the purified $20 \mathrm{~S}$ proteasome with an $\mathrm{IC}_{50}$ value of $5.3 \mu \mathrm{M}(38)$. However, the synthesized $\mathrm{Cu}$ complexes exhibit cancer-specific proteasome-inhibitory and apoptosis inducing activities. In combination with the results of biological study and molecular docking simulation, we can draw the following conclusion: these three complexes, but not ligands or $\mathrm{CuCl}_{2}$, could enter tumor cells and directly bind with catalytic site of subunit $\beta 5$ by forming a number of hydrogen bonds and hydrophobic interactions and therefore inhibit chemotrypsin-like activity and induce tumor cell death (Fig. 7). This study indicates that these copper complexes and other similar complexes could act as potent proteasome inhibitors and have great potential to be developed into new metal-based anticancer agents.

\section{Acknowledgements}

The present study was supported by grants from the Project of Shandong Province Higher Educational Science and Technology Program to Zhen Zhang (no. J15LC22), the National Science Foundation of China to Caifeng Bi (no. 21371161), the Science and Technology Program of Jining to Zhen Zhang (no. 2015-92) and the Doctoral Foundation of Jining Medical University to Zhen Zhang (no. JY14QD06).

\section{References}

1. Schmitt SM, Frezza M and Dou QP: New applications of old metal-binding drugs in the treatment of human cancer. Front Biosci (Schol Ed) 4: 375-391, 2012.
2. Santini C, Pellei M, Gandin V, Porchia M, Tisato F and Marzano C: Advances in copper complexes as anticancer agents. Chem Rev 114: 815-862, 2014.

3. Krajčiová D, Melník M, Havránek E, Forgácsová A and Mikuš P: Copper compounds in nuclear medicine and oncology. J Coord Chem 67: 1493-1519, 2014.

4. Buac D, Schmitt S, Ventro G, Kona FR and Dou QP: Dithiocarbamate-based coordination compounds as potent proteasome inhibitors in human cancer cells. Mini Rev Med Chem 12: 1193-1201, 2012.

5. Chen D, Cui QC, Yang H and Dou QP: Disulfiram, a clinically used anti-alcoholism drug and copper-binding agent, induces apoptotic cell death in breast cancer cultures and xenografts via inhibition of the proteasome activity. Cancer Res 66: 10425-10433, 2006.

6. Zhai S, Yang L, Cui QC, Sun Y, Dou QP and Yan B: Tumor cellular proteasome inhibition and growth suppression by 8-hydroxyquinoline and clioquinol requires their capabilities to bind copper and transport copper into cells. J Biol Inorg Chem 15: 259-269, 2010

7. Chen D, Cui QC, Yang H, Barrea RA, Sarkar FH, Sheng S, Yan B, Reddy GP and Dou QP: Clioquinol, a therapeutic agent for Alzheimer's disease, has proteasome-inhibitory, androgen receptor-suppressing, apoptosis-inducing, and antitumor activities in human prostate cancer cells and xenografts. Cancer Res 67: 1636-1644, 2007.

8. Adsule S, Barve V, Chen D, Ahmed F, Dou QP, Padhye S and Sarkar FH: Novel Schiff base copper complexes of quinoline-2 carboxaldehyde as proteasome inhibitors in human prostate cancer cells. J Med Chem 49: 7242-7246, 2006.

9. Creaven BS, Czeglédi E, Devereux M, Enyedy ÉA, FoltynArfa Kia A, Karcz D, Kellett A, McClean S, Nagy NV, Noble A, et al: Biological activity and coordination modes of copper(II) complexes of Schiff base-derived coumarin ligands. Dalton Trans 39: 10854-10865, 2010.

10. Zhang Z, Bi C, Fan Y, Zhang N, Deshmukh R, Yan X, Lv X, Zhang P, Zhang X and Dou QP: L-Ornithine Schiff base-copper and -cadmium complexes as new proteasome inhibitors and apoptosis inducers in human cancer cells. J Biol Inorg Chem 20: 109-121, 2015.

11. Nalepa G, Rolfe M and Harper JW: Drug discovery in the ubiquitin-proteasome system. Nat Rev Drug Discov 5: 596-613, 2006.

12. Peters JM, Cejka Z, Harris JR, Kleinschmidt JA and Baumeister W: Structural features of the $26 \mathrm{~S}$ proteasome complex. J Mol Biol 234: 932-937, 1993.

13. Groll M, Ditzel L, Löwe J, Stock D, Bochtler M, Bartunik HD and Huber R: Structure of 20S proteasome from yeast at $2.4 \mathrm{~A}$ resolution. Nature 386: 463-471, 1997.

14. Groll M, Heinemeyer W, Jäger S, Ullrich T, Bochtler M, Wolf DH and Huber R: The catalytic sites of $20 \mathrm{~S}$ proteasomes and their role in subunit maturation: A mutational and crystallographic study. Proc Natl Acad Sci USA 96: 10976-10983, 1999.

15. Adams J: The proteasome: A suitable antineoplastic target. Nat Rev Cancer 4: 349-360, 2004.

16. Frezza M, Schmitt S and Dou QP: Targeting the ubiquitinproteasome pathway: An emerging concept in cancer therapy. Curr Top Med Chem 11: 2888-2905, 2011.

17. Lopes UG, Erhardt P, Yao R and Cooper GM: p53-dependent induction of apoptosis by proteasome inhibitors. J Biol Chem 272: 12893-12896, 1997.

18. An B, Goldfarb RH, Siman R and Dou QP: Novel dipeptidyl proteasome inhibitors overcome $\mathrm{Bcl}-2$ protective function and selectively accumulate the cyclin-dependent kinase inhibitor p27 and induce apoptosis in transformed, but not normal, human fibroblasts. Cell Death Differ 5: 1062-1075, 1998.

19. Rajkumar SV, Richardson PG, Hideshima T and Anderson KC: Proteasome inhibition as a novel therapeutic target in human cancer. J Clin Oncol 23: 630-639, 2005.

20. Verani CN: Metal complexes as inhibitors of the $26 \mathrm{~S}$ proteasome in tumor cells. J Inorg Biochem 106: 59-67, 2012.

21. Unno M, Mizushima T, Morimoto Y, Tomisugi Y, Tanaka K, Yasuoka $\mathrm{N}$ and Tsukihara T: The structure of the mammalian $20 \mathrm{~S}$ proteasome at 2.75 A resolution. Structure 10: 609-618, 2002.

22. Zhang Z, Bi C, Schmitt SM, Fan Y, Dong L, Zuo J and Dou QP: 1,10-Phenanthroline promotes copper complexes into tumor cells and induces apoptosis by inhibiting the proteasome activity. J Biol Inorg Chem 17: 1257-1267, 2012. 
23. Zhang Z, Bi C, Buac D, Fan Y, Zhang X, Zuo J, Zhang P, Zhang N, Dong L and Dou QP: Organic cadmium complexes as proteasome inhibitors and apoptosis inducers in human breast cancer cells. J Inorg Biochem 123: 1-10, 2013.

24. Zhang Z, Bi C, Fan Y, Wang H and Bao Y: Cefepime, a fourthgeneration cephalosporin, in complex with manganese, inhibits proteasome activity and induces the apoptosis of human breast cancer cells. Int J Mol Med 36: 1143-1150, 2015.

25. Zhang N, Fan YH, Zhang Z, Zuo J, Zhang PF, Wang Q, Liu SB and Bi CF: Syntheses, crystal structures and anticancer activities of three novel transition metal complexes with Schiff base derived from 2-acetylpyridine and 1-tryptophan. Inorg Chem Commun 22: 68-72, 2012.

26. Daniel KG, Chen D, Orlu S, Cui QC, Miller FR and Dou QP: Clioquinol and pyrrolidine dithiocarbamate complex with copper to form proteasome inhibitors and apoptosis inducers in human breast cancer cells. Breast Cancer Res 7: R897-R908, 2005.

27. Chen D, Peng F, Cui QC, Daniel KG, Orlu S, Liu J and Dou QP: Inhibition of prostate cancer cellular proteasome activity by a pyrrolidine dithiocarbamate-copper complex is associated with suppression of proliferation and induction of apoptosis. Front Biosci 10: 2932-2939, 2005.

28. Jones G, Willett P and Glen RC: Molecular recognition of receptor sites using a genetic algorithm with a description of desolvation. J Mol Biol 245: 43-53, 1995.

29. Kazuo N, Huang DR and Wang QR: Infrared and Raman spectra of inorganic and coordination compounds. Chemical Industry Press, Beijing, 1988.

30. Gong QJ, Jin WJ, Dong C and Liu CS: Synthesis of new fluorescence reagent: 4-Aminoantipyrine aromatic Schiff bases. Appl Chem 17: 227-229, 2000.
31. Li B and Dou QP: Bax degradation by the ubiquitin/proteasome-dependent pathway: Involvement in tumor survival and progression. Proc Natl Acad Sci USA 97: 3850-3855, 2000.

32. Orlowski RZ and Kuhn DJ: Proteasome inhibitors in cancer therapy: Lessons from the first decade. Clin Cancer Res 14: 1649-1657, 2008.

33. Kane RC, Bross PF, Farrell AT and Pazdur R: Velcade: U.S. FDA approval for the treatment of multiple myeloma progressing on prior therapy. Oncologist 8: 508-513, 2003.

34. Dou QP and Zonder JA: Overview and perspective of proteasome inhibitor-based anti-cancer therapies: Bortezomib and second generation proteasome inhibitors versus future generation inhibitors of ubiquitin-proteasome system. Curr Cancer Drug Targets 14: 517-536, 2014.

35. Lee EC, Fitzgerald M, Bannerman B, Donelan J, Bano K, Terkelsen J, Bradley DP, Subakan O, Silva MD, Liu R, et al: Antitumor activity of the investigational proteasome inhibitor MLN9708 in mouse models of B-cell and plasma cell malignancies. Clin Cancer Res 17: 7313-7323, 2011.

36. Shirley M: Ixazomib: First Global Approval. Drugs 76: 405-411, 2016.

37. Offidani M, Corvatta L, Gentili S, Maracci L and Leoni P: Oral ixazomib maintenance therapy in multiple myeloma. Expert Rev Anticancer Ther 16: 21-32, 2016.

38. Milacic V, Chen D, Giovagnini L, Diez A, Fregona D and Dou QP: Pyrrolidine dithiocarbamate-zinc(II) and -copper(II) complexes induce apoptosis in tumor cells by inhibiting the proteasomal activity. Toxicol Appl Pharmacol 231: 24-33, 2008. 